\title{
A abordagem fisioterapeuta na disfunção erétil
}

\author{
A physical therapist approach to erectile dysfunction \\ Un enfoque de fisioterapeuta para la disfunción eréctil
}

Recebido: 27/09/2021 | Revisado: 02/10/2021 | Aceito: 07/10/2021 | Publicado: 10/10/2021

\author{
Adryana Stéfany Gomes Franco \\ ORCID: https://orcid.org/0000-0003-0110-2837 \\ Instituto Educacional Santa Catarina - Faculdade Guaraí, Brasil \\ E-mail: adryanaastefany@gmail.com \\ Mônica Neres Cardoso \\ ORCID: https://orcid.org/0000-0003-2180-7252 \\ Instituto Educacional Santa Catarina - Faculdade Guaraí, Brasil \\ E-mail: cardosomonica886@gmail.com \\ Karla Camila Correia da Silva \\ ORCID: https://orcid.org/0000-0003-1538-7028 \\ Instituto Educacional Santa Catarina - Faculdade Guaraí, Brasil \\ E-mail: karlacamilac@yahoo.com.br
}

\begin{abstract}
Resumo
A disfunção erétil (DE) é a incapacidade de atingir ou manter uma ereção forte o suficiente para permitir a relação sexual. A DE pode ser uma incapacidade total de conseguir uma ereção, ou uma capacidade inconsistente e imprevisível de alcançar uma ereção satisfatória, ou mesmo uma tendência de manter uma ereção por um curto período. Antes de iniciar qualquer tipo de tratamento acerca da disfunção erétil deve se rastrear a causa e obedecer aos critérios, assim evitando cirurgia ou qualquer tipo de procedimentos invasivos, antes de tratar as questões clínicas e fatores de riscos. São disponíveis diversos tratamentos para disfunção, diversas opções de tratamento fisioterapêuticos ou não já estão disponíveis: eletroterapia, aconselhamento psicossexual, o uso de dispositivos de vácuo externas, medicamentos, terapia de injeção intracavernosa e o uso de uma prótese peniana. Intervenções fisioterapêuticas fornecem métodos de tratamentos não-invasivos, indolor, de fácil realização e baixo custo. O objetivo deste trabalho é descrever sobre a disfunção erétil como um problema de saúde e seu tratamento através de uma abordagem fisioterapêutica. A metodologia utilizada consistiu em estudo descritivo, relativo e atual, através de levantamento bibliográfico científico. Com base nas pesquisas realizadas, considera-se que a fisioterapia é eficaz na prevenção e no tratamento da disfunção erétil. Contudo, necessita-se de mais estudos para o aperfeiçoamento fisioterapêutico e descoberta de novas técnicas a ser utilizadas.
\end{abstract}

Palavras-chave: Tratamento; Fisioterapia; Disfunção erétil.

\begin{abstract}
Erectile dysfunction (ED) is the inability to achieve or maintain an erection strong enough to allow intercourse. ED can be a total inability to achieve an erection, or an inconsistent and unpredictable ability to achieve a satisfactory erection, or even a tendency to maintain an erection for a short period of time. Before to start any type of treatment for erectile dysfunction, the cause should be screened and the criteria followed, thus avoiding surgery or any type of invasive procedure, before treating clinical issues and risk factors. Various treatments are available for erectile dysfunction Several treatment options for erectile dysfunction are currently available: electrotherapy, psychosexual counseling, the use of external vacuum devices, medications, intracavernous injection therapy, and the use of a prosthetic prosthesis. penis. Physiotherapeutic interventions provide non-invasive, painless, easy-to-perform, and lowcost treatment methods. The objective of this work is to describe erectile dysfunction as a health problem and its treatment through a physiotherapy approach. The methodology used consisted of a descriptive, relative and current study, through a scientific bibliographic survey. Based on research, physical therapy is considered effective in preventing and treating erectile dysfunction. However, more studies are needed to improve physical therapy and discover new techniques to use.
\end{abstract}

Keywords: Treatment; Physiotherapy; Erectile dysfunction.

\section{Resumen}

La disfunción eréctil (DE) es incapaz de lograr o mantener una erección fuerte o suficiente para permitir el coito. La DE puede ser una incapacidad total para lograr una erección, o una habilidad inconsistente e impredecible para lograr una erección satisfactoria, o la misma tendencia a mantener una erección por un período corto de tiempo. Antes El inicio de cualquier tipo de tratamiento relacionado con la disfunción eréctil debe ser cribado según los criterios, evitando también la cirugía o cualquier tipo de procedimiento invasivo, antes de tratar problemas clínicos y factores 
precipitantes. São Paulo tiene varios tratamientos para la disfunción eréctil, diferentes opciones de tratamiento para la disfunción eréctil tan pronto como estén disponibles: electroterapia, asesoramiento psicosexual o uso de una aspiradora externa, medicación, terapia de inyección intracavernosa y uso de prótesis de pene. Las intervenciones fisioterapéuticas proporcionan métodos de tratamiento de custodia no invasivos, indoloros y fáciles de realizar. El objetivo de este trabajo es dar a conocer la disfunción eréctil como problema de salud y su tratamiento a través de un enfoque de fisioterapia. La metodología utilizada consiste en un estudio descriptivo, relativo y actual, a través de un relevamiento bibliográfico científico. Con base en las investigaciones realizadas, se considera que la fisioterapia es eficaz para prevenir y no tratar la disfunción eréctil. Sin embargo, se necesitan más estudios para el entrenamiento de fisioterapia y la eliminación de nuevas técnicas que se utilizarán.

Palabras clave: Tratamiento; Fisioterapia; Disfunción eréctil.

\section{Introdução}

A disfunção sexual é definida como uma complicação que ocorre em qualquer fase do ciclo de resposta sexual. As fases do ciclo de resposta sexual incluem; desejo, excitação, orgasmo e resolução. A disfunção sexual é extremamente comum entre mulheres e homens, e há tratamento eficaz disponível. A disfunção sexual é qualquer problema físico ou psicológico que impede você ou seu parceiro de obter satisfação sexual. A disfunção erétil é o mais frequente dos distúrbio sexuais que acomete a população masculina, convertendo-se em um problema de saúde comum que afeta homens de todas as idades, sendo mais comum com o aumento da idade. O tratamento geralmente pode ajudar os homens que sofrem da DE.

Ter problemas de ereção de vez em quando não é necessariamente um motivo para se preocupar. No entanto, se a disfunção erétil for um problema contínuo, pode causar estresse, afetar a autoconfiança e contribuir para problemas de relacionamento. Problemas para obter ou manter uma ereção também podem ser um sinal de uma condição de saúde préexistente que precisa de tratamento e um fator de risco para doenças cardíacas.

A disfunção erétil é um problema que afeta milhões de homens em todo o mundo e tem grande impacto na qualidade de vida deles e de suas parceiras. Ainda é um assunto tabu e, por isso, os afetados consultam pouco o médico. Porém, é preciso falar sobre essa patologia para desmistificá-la, pois, além disso, a disfunção tem tratamento. Às vezes, o tratamento é voltado para uma condição pré-existente, que é suficiente para reverter a disfunção erétil. Em outros casos, medicamentos ou outros tratamentos diretos podem ser necessários.

No entanto, poucos procuram ajuda, questões como culturais, religiosas, vergonha e desinformação são algumas das causas de sua grande prevalência. Não sendo uma ameaça a vida, há um impacto na vida social e interpessoal do indivíduo, comprometendo a qualidade de vida de homens e mulheres (Falchi, 2016).

A disfunção erétil (DE) é a incapacidade recorrente de obter e manter uma ereção que permita atividade sexual satisfatória. As causas podem ser classificadas como de etiologia psicológica, orgânica ou ainda uma combinação de ambas. As causas psicogênicas mais comuns incluem ansiedade de desempenho, transtornos psiquiátricos (ansiedade e depressão) e conflitos no relacionamento. Entre os fatores orgânicos, encontram-se causas vasculares, endócrinas, neurológicas, relacionadas a drogas e a intervenções urológicas. Homens com disfunção erétil tem o desempenho ruim no trabalho, problemas com relacionamento com a parceira e insatisfação pessoal com a vida sexual (Moreira Jr. et al, 2014).

A DE é uma doença comum que afeta negativamente a qualidade de vida dos homens que a sofrem, sua prevalência varia entre diferentes países, culturas e raças.

A disfunção erétil é definida como a falha persistente em alcançar e manter ereções de rigidez suficiente para a penetração durante a relação sexual, onde costuma ter várias causas. Portanto, a avaliação diagnóstica para essa deficiência deve incluir uma avaliação dos achados de um exame do estado psicológico, hormonal, neurológico e vascular do paciente. Em muitos casos, uma combinação de fatores está envolvida.

DE ocasional não é incomum. Muitos homens experimentam isso em momentos de estresse, quando ocorrida com certa frequência, no entanto, pode ser um sinal de problemas de saúde que precisa de tratamento. Também pode ser um sinal de 
dificuldades emocionais ou de relacionamento que precisam ser resolvidas por um profissional.

O papel dos músculos perineais no mecanismo erétil ainda está aberto para debate. Alguns estudos apontam evidências de que normalmente há aumento da atividade dos músculos isquiocavernosos e bulbocavernosos durante o coito. Essa atividade muscular contribui para o aumento da pressão intracavernosa. Durante as últimas duas décadas, a pesquisa se concentrou no desenvolvimento de técnicas de diagnóstico da disfunção erétil masculina, a fim de fornecer o tratamento mais adequado.

Antes de iniciar o tratamento da disfunção erétil deve se obter o reconhecimento da causa e obedecer a critérios, evitando-se procedimentos invasivos e cirurgias antes de se tratar ou minimizar as questões clínicas e os fatores de risco para tal disfunção.

A metodologia utilizada consistiu em estudo descritivo, relativo e atual, através de levantamento bibliográfico científico. O objetivo deste trabalho é descrever sobre a disfunção erétil como um problema de saúde e seu tratamento através de uma abordagem fisioterapêutica.

\section{Metodologia}

Para alcançar a meta proposta nesta etapa levando em consideração o que diz Stake (2011), a metodologia de pesquisa pode ser compreendida com relação a sua natureza, abordagem, objetivos e procedimentos de coleta de dados.

Trata-se de um estudo de revisão bibliográfica, de pesquisa seletiva, descritiva de análise documental e atual, realizada durante o período de fevereiro à junho de 2021. Através de pesquisas nas bases eletrônicas de comprovação científica, SCIELO (Scientific Eletronic Library Online), PubMed (Medline), Lilacs (Medline), EMBASE, CINAHL e PEDro com as palavras-chaves: Fisioterapia, disfunção erétil e tratamento. Os termos foram pesquisados em dois idiomas, o inglês e o português. Foram escolhidos artigos compreendidos entre 2010 e 2021.

A seleção dos artigos deu-se por leitura analítica dos resumos e em caso de dúvidas fez-se a leitura completa do artigo. As buscas foram feitas num total de 47 (quarenta e sete) referenciais, onde foram incluídos 27 (vinte e sete) referências, os critérios de inclusão foram: artigos com delimitação do período de publicação de até dez anos, disponíveis completos na íntegra nas bases de dados já citados, com a proposição de que abordassem a atuação fisioterapêutica nas questões da saúde do homem e disfunções sexuais masculinas assim como femininas.

Os critérios de exclusão foram: resultados que não configurassem artigos científicos, isto é, dissertações, teses, resumos, dentre outros documentos. Foram excluídos também 20 (vinte) artigos, aqueles que não tinham como foco especificamente a atuação da fisioterapia nas disfunções sexuais e na saúde do homem e artigos superior ao ano de 2010.

\section{Revisão de Literatura}

\subsection{Disfunção Erétil}

A disfunção erétil é a incapacidade de atingir e ou manter uma ereção peniana e ter desempenho sexual satisfatório; é considerada o segundo problema de disfunção sexual mais frequente em homens, depois da ejaculação precoce, com uma prevalência de aproximadamente 30\%. É uma doença que tem uma enorme prevalência no mundo, sendo mais frequente em idosos (Biggers, 2017).

Segundo Abreu (2015), desde os tempos antigos até os dias atuais a DE é considerada uma condição que sempre afetou os homens. A maioria dos casos de disfunção erétil tem origem orgânica, principalmente devido a doenças vasculares, mas também está associada a fatores psicológicos, neurológicos ou hormonais, ou a alterações estruturais. A terapia medicamentosa com inibidores da -fosfodiesterase tem eficácia clínica, mas há pacientes que não respondem a ela. Por este 
motivo, ondas de choque de baixa intensidade foram utilizadas para melhorar a vascularização e o fluxo sanguíneo do pênis, conseguindo assim ereções que melhoram a qualidade de vida sexual. Esta revisão inclui diferentes estudos que demonstram a eficácia desse tratamento. Os sintomas incluem: problemas em obter ereção, problemas em manter ereção e diminuição do desejo sexual (Mayo Clinic, 2018).

As causas mais frequentes de disfunção erétil são psicogênicas (psicopatias, mau relacionamento com o parceiro, problemas profissionais ou sociais, experiências anteriores ruins, falsas crenças, desinformação sexual etc.), doenças cardiovasculares e fatores de risco (tabagismo, hipercolesterolemia, obesidade etc.), diabetes, próstata, depressão, traumas raquimedular, paraplegias, esclerose múltipla, sedentarismo, bem como muitos dos tratamentos médicos e cirúrgicos que se aplicam para resolvê-los. As principais causas psicológicas são: depressão, ansiedade, estresse, problemas de relacionamento devido ao estresse, falta de comunicação e preocupações (Mayo Clinic, 2018).

Já existem evidências suficientes sobre a DE como sintoma inicial de patologias cardiovasculares, portanto o urologista deve ter um papel ativo em seu estudo e prevenção. Além disso, as patologias cardiovasculares são frequentes em pacientes com DE e isso está presente em muitas doenças cardiovasculares. A DE e as doenças vasculares compartilham a mesma patogênese pela via do óxido nítrico, levando à alteração da vasodilatação dependente do endotélio e subsequentes anormalidades estruturais vasculares. Cardiopatias, sedentarismo, obesidade, tabagismo, hipercolesterolemia e síndrome metabólica, são considerados fatores predisponentes a DE, que podem ser reduzidos com tratamento adequado, melhora na qualidade de vida, além do acompanhamento psicológico (Peterle \& Bueno, 2016).

O processo de ereção tem por base o relaxamento das fibras musculares lisas dos corpos cavernosos, o que permite um maior fluxo sanguíneo arterial aos espaços lacunares, com concomitante vasodilatação das artérias cavernosas. Essa distensão dos espaços lacunares comprime o plexo venoso subalbuginial contra a rígida túnica albugínea, diminuindo assim o retorno venoso (mecanismo venoclusivo). A pressão intracavernosa se eleva, promovendo a rigidez peniana. (Moreira Jr. Et al, 2014).

A DE pode ocorrer devido a problemas em qualquer estágio do processo de ereção. Uma ereção é o resultado do aumento do fluxo sanguíneo para o pênis. O fluxo sanguíneo geralmente é estimulado por pensamentos sexuais ou pelo contato direto com o pênis. Quando um homem está sexualmente excitado, os músculos do pênis relaxam. Isso permite um maior fluxo sanguíneo através das artérias penianas, enchendo duas câmaras dentro do pênis. À medida que as câmaras se enchem de sangue, o pênis fica rígido. O cérebro é uma zona erógena frequentemente esquecida. A excitação sexual começa no sistema nervoso central e vai progredindo. (Mayo Clinic, 2018).

A depressão, estresse e ansiedade são condições que pode diminuir o desejo e pode levar à disfunção erétil. O estresse da vida diária, adicionado à ansiedade que podendo acarretar em depressão. Que ironicamente, muitos dos medicamentos usados para tratar a depressão também podem suprimir o impulso sexual e dificultar a ereção além de atrasar o orgasmo. O impacto emocional causado pela disfunção erétil no homem se torna depressivo, visto que, compromete sua autoestima, pois em tese a mesma está interligada à sua masculinidade, isto é, seu potencial eretivo ou sexual (Michiles, 2010).

O uso excessivo de álcool pode interferir nas ereções, mas os efeitos geralmente são temporários. Beber moderadamente - pode ter benefícios para a saúde, como reduzir os riscos de doenças cardíacas. E esses riscos são semelhantes aos riscos de disfunção erétil. Droga como anfetaminas, cocaína e maconha também podem causar problemas sexuais. (Mayo Clinic, 2018).

Vivemos em uma sociedade em que ocorre uma excessiva valorização do poder de conquista dos homens, onde esse tema está também voltado para a sua sexualidade, e o mesmo não tendo essa habilidade devido à problemática da 21 disfunção erétil ocasionará uma série de conflitos, como ansiedade, medo, depressão, dentre outros (Michiles, 2010). 
Uma longa lista de medicamentos comuns pode causar disfunção erétil, incluindo certos medicamentos para pressão arterial, analgésicos e antidepressivos (Peterle \& Bueno, 2016). Assim confirmando a importância de praticar exercícios regularmente, fazendo mudanças no estilo de vida que promovam o bem-estar e o relaxamento, dormir o suficiente e procurar ajuda profissional quando apropriado. (Abreu,2015)

A maior parte dos problemas no funcionamento dos mecanismos de ereção se deve, por um lado, ao déficit circulatório, e, por outro, à esclerose dos pequenos vasos sanguíneos, além da fibrose progressiva dos corpos cavernosos. (Peterle \& Bueno, 2016).

Essa fibrose-esclerose e essa insuficiência circulatória ocorrem tanto no diabetes quanto na hipertensão arterial, na dislipidemia do colesterol ou nas demais aterosclerose. Também em doenças de origem desconhecida, como fibrose dos corpos cavernosos ou doença de La Peyronie. Portanto, a aplicação de ondas de choque de baixa intensidade proporcionará uma melhora significativa, pois a fibrose e a esclerose são combatidas e uma nova vascularização é produzida. $\mathrm{O}$ tratamento vai gerar seus efeitos de forma progressiva ao longo do tempo. Este tratamento não exclui outros tipos de terapias que são utilizadas na fisioterapia, como o treinamento dos músculos do assoalho pélvico, o 'biofeedback', a estimulação das fibras motoras do nervo pudendo etc. (Peterle \& Bueno, 2016).

Na disfunção erétil, a incapacidade de atingir e manter uma ereção que permite uma relação sexual satisfatória pode ser tratada com resultados ideais pela aplicação de ondas de baixa intensidade. "As ondas de choque (de alta intensidade) são utilizadas desde a década de 1980 no tratamento de cálculos do trato urinário (litotripsia extracorpórea por ondas de choque). Mas, além disso, as ondas de choque de baixa intensidade já vinham demonstrando uma poderosa eficácia antifibrótica, sendo utilizadas com grande sucesso na fisioterapia para o tratamento de lesões articulares e degeneração fibrosa dos ligamentos. Esse efeito das ondas de choque de baixa intensidade é chamado de neoangiogênese, ou seja, o surgimento de uma nova circulação após a destruição do tecido fibroso. (Peterle \& Bueno, 2016).

O primeiro passo para obter uma boa avaliação diagnóstica da DE é obter uma história sexual, médica e psicossexual detalhada do paciente. É um caminho por meio dessa história clínica que se pode identificar as prováveis causas da dilapidação da DE, bem como definir seu valor e naturalidade. A história sexual do paciente deve incluir informações sobre o início e a duração do problema, relações sexuais atuais e anteriores, descrição da rigidez e duração dos estímulos sexuais, ereções noturnas e matinais, circunstâncias associadas, como o estado emocional real (ansiedade, estresse, etc.), e o relato de possíveis problemas de excitação, ejaculação e / ou orgasmo. A fim de ser capaz de avaliar de forma sensata e rigorosa todas as dimensões da disfunção erétil, os seguintes questionários validados foram desenvolvidos: o Índice Internacional de Disfunção Erétil e a Pesquisa de Saúde Sexual para Homens. (Mayo Clinic, 2018).

\subsection{Causas}

A excitação sexual masculina é um processo complexo que envolve o cérebro, hormônios, emoções, nervos, músculos e vasos sanguíneos. A disfunção erétil pode ser o resultado de um problema com um desses fatores. Da mesma forma, o estresse e as preocupações com a saúde mental podem levar à disfunção erétil ou piorá-la. (Peterle \& Bueno, 2016).

A disfunção erétil é uma patologia multifatorial. A ereção é um fenômeno neuro vascular que ocorre sob controle hormonal e em um ambiente psicológico específico. Desta forma podemos entender que qualquer patologia neurológica, vascular, hormonal ou psicológica pode alterar os mecanismos de ereção. As principais causas da impotência são aquelas relacionadas às doenças cardiovasculares, como hipertensão, diabetes, colesterol alto, tabagismo, sedentarismo e obesidade. (Mayo Clinic, 2018).

Existem também outras causas físicas, como álcool, drogas, doenças crônicas (especialmente dos pulmões, coração, fígado ou rins), alterações hormonais (testosterona, prolactina, hormônio da tireoide), alterações neurológicas (esclerose 
múltipla ou lesões da medula espinhal, por exemplo). Muitas dessas patologias são mais frequentes em pessoas mais velhas, portanto, os problemas de ereção aumentam com a idade. Às vezes, a disfunção erétil se deve a uma combinação de problemas físicos e psicológicos. Por exemplo, uma doença física leve que retarda sua resposta sexual pode deixá-lo ansioso para manter uma ereção. Essa ansiedade pode causar ou piorar a disfunção erétil. (Moreira Jr. et al, 2014).

\subsection{Fatores de risco}

Vários fatores de risco podem contribuir para a disfunção erétil.

\subsubsection{Idade}

Conforme envelhecemos, as ereções podem demorar mais para se desenvolver e podem não ser tão firmes. Para conseguir e manter uma ereção, podendo ser necessário um contato mais direto com o pênis. As ereções envolvem principalmente os vasos sanguíneos. E as causas mais comuns de disfunção erétil em homens mais velhos são condições que bloqueiam o fluxo sanguíneo para o pênis. Isso inclui o endurecimento das artérias aterosclerose e diabetes. Outra causa pode ser uma veia com defeito que permite que o sangue drene muito rapidamente do pênis. (Peterle \& Bueno, 2016).

\subsubsection{Vascular}

Sendo muito comum. Ocorre quando pouco sangue atinge o pênis (arterial) ou não é retido adequadamente nos corpos cavernosos (venno-oclusivos), causando um escape de sangue que impede alcançar e manter a rigidez adequada. (Peterle \& Bueno, 2016).

Nesses homens com fatores de risco cardiovascular, a disfunção erétil pode ser o primeiro sintoma "sentinela" de doença cardiovascular que irá progredir com o tempo. Competindo a necessidade de tratar problemas de ereção e é muito importante corrigir esses fatores de risco vascular que podem desencadear um evento cardíaco ou vascular mais grave. (Peterle \& Bueno, 2016).

\subsubsection{Hormonal ou Endócrino}

Quando o corpo produz menos hormônio masculino (testosterona) do que o necessário. A testosterona que é a responsável por aumentar o desejo sexual, aumenta a frequência das relações sexuais e ereções matinais. Um déficit de testosterona favorece a disfunção erétil. (Peterle \& Bueno, 2016).

\subsubsection{Neurológico}

Ocorre quando há problemas na transmissão de ordens que o cérebro e a medula espinhal enviam ao pênis, através dos nervos eretores. Diabetes, doenças da medula espinhal e cirurgias realizadas para câncer de próstata, bexiga e reto (danos aos nervos eretores) produzem esse tipo de impotência. Além de acidentados que lesionam a medula espinhal, como traumas raquimedulares, paraplegias e tetraplegias. Esses pacientes com causa neurológica têm problemas para iniciar uma ereção e o tratamento é mais complexo. (Antonioli, Simões, 2010).

\subsubsection{Medicamentoso}

Muitos medicamentos usados para tratar doenças como hipertensão (especialmente betabloqueadores e tiazidas) ou depressão podem afetar a função erétil. Drogas psicotrópicas usadas para tratar doenças do sistema nervoso geralmente afetam a ereção. (Peterle \& Bueno, 2016). 


\subsubsection{Tabagismo}

Sobre se a disfunção erétil é reversível associando o tratamento a suspensão do uso. Existem estudos que respondem afirmativamente, embora vinculem a recuperação ao tempo que você fuma. Portanto, se o paciente fumou por um curto período, ele terá uma melhor chance de recuperar a função normal de seu pênis do que se o fizesse por muitos anos. Uma revisão de 83 estudos publicados pela Sexual Medicine Reviews investiga essa possibilidade, além de insistir na evidência de que o tabagismo é um fator de risco para sofrer de problemas de ereção.

O tabaco também prejudica outros aspectos da saúde sexual masculina, como a infertilidade, pois provoca alterações na fertilidade ao deteriorar a produção de espermatozoides, tanto em qualidade quanto em quantidade, além de dificultar sua mobilidade. (Heidelbaugh, 2010)

\subsubsection{Psicológico}

A resposta sexual se origina no cérebro e depende de um equilíbrio entre os impulsos excitatórios e inibitórios no Sistema Nervoso Central. O cérebro processa todas as informações que recebe e emite as ordens apropriadas para o início da ereção. (Antonioli, Simões, 2010).

Nestes casos, o mecanismo de rigidez peniana é normal, mas a ereção é dificultada por problemas psicológicos que podem ser devidos à ansiedade de desempenho (medo de não obter uma ereção, medo de falhar), problemas de relacionamento, depressão ou outros problemas psicológicos. O estresse de qualquer tipo pode afetar o ato sexual. (Heidelbaugh, 2010)

Muitos pacientes podem ter inicialmente um componente vascular que causa disfunção erétil leve. É muito comum que a ansiedade de desempenho (medo de falhar) se acrescente à disfunção erétil.

\subsubsection{Prevenção}

Aas medidas de tratamento são compostas pela mudança dos hábitos de vida, aconselhamento, psicoterapia/terapia sexual e os fármacos inibidores da fosfodiesterase (Theves, 2015).

A melhor maneira de prevenir a disfunção erétil é fazer escolhas de estilo de vida saudáveis e controlar quaisquer problemas de saúde existentes. Por exemplo:

- Trabalhe com seu médico para controlar o diabetes, doenças cardíacas ou outras condições crônicas de saúde.

- Consulte o seu médico para checkups regulares e testes de triagem médica.

- Não fumar, limite ou evite o álcool e não use drogas ilegais.

- Exercite regularmente.

- Tome medidas para reduzir o estresse.

- Obtenha ajuda para ansiedade, depressão ou outros problemas de saúde mental.

\subsection{Tratamentos Fisioterápicos na disfunção erétil}

A disfunção erétil é um problema profundamente pessoal e angustiante que descreve uma condição em que uma ereção não é possível ou não é suficiente para a tarefa desejada da atividade sexual. É uma condição que pode ter múltiplas causas e, portanto, você deve discuti-la com o médico e manter o acompanhamento com o mesmo. O tratamento da DE é específico para cada paciente. Primeiramente há a identificação e controle da condição subjacente. Além disso, pode-se fazer o uso de medicamentos orais, injeções, supositório uretral, reposição de testosterona, bombas cirurgia, implantes, exercício físico, aconselhamento psicológico, tratamento alternativos e mudanças no estilo de vida (Mayo Clinic, 2018).

Na maior parte dos casos, o prognóstico é positivo, visto que há inúmeras alternativas de tratamento (Biggers, 2017). 
Entretanto, isso pode variar de acordo com a causa (Javaroni, 2018).

A fisioterapia não possui uma especialidade direcionada a saúde do homem, no entanto, os cuidados ligados a esse público são aplicados em seus diversos segmentos, nos âmbitos da prevenção, promoção e reabilitação da saúde. A atuação fisioterapêutica destaca-se como fundamental, considerando que, o profissional possui competência para avaliar e executar suas atividades com autonomia, em todos os níveis da atenção básica em saúde, da mesma forma que individual ou coletivo. (Javaroni, 2018).

A fisioterapia é responsável por ter um ótimo resultado em pacientes com disfunção erétil de origem vascular (devido à alta pressão (hipertensão, diabetes etc. que fecha os vasos sanguíneos que dão a ereção). (Moreira Jr. et al, 2014).

Diferentes opções de tratamento para disfunção erétil já estão disponíveis. As intervenções fisioterapêuticas fornecem estratégias de tratamentos não-invasivos, indolor, de fácil desempenho e custo baixo, diferentemente de outras formas de tratamento e intervenções. Os métodos que podem ser utilizados para o tratamento da DE são a psicoterapia, as próteses penianas, as cirurgias e os medicamentos, administrados por via oral ou injetável, em que as injeções são aplicadas diretamente no pênis (Jesus \& Lima, 2018).

Para a adesão da paciente ao tratamento e o sucesso da intervenção terapêutica é importante observar como cada uma percebe seu problema e as consequências trazidas pela patologia para sua vida, de forma que, mesmo apresentando sinais e sintomas semelhantes, possam adotar diferentes estratégias para enfrentar o problema (Sousa et al., 2011).

\subsubsection{Vacuoterapia}

Um dispositivo de constrição a vácuo (VCD) é uma bomba externa que um homem com disfunção erétil (DE) pode usar para obter e manter uma ereção. A bomba ajuda o pênis a ficar ereto e uma faixa presa à bomba ajuda a manter a ereção. A vacuoterapia é uma opção não invasiva de tratamento, por ex: A figura 2. (Heidelbaugh, 2010)

A terapia a vácuo (VT) utiliza pressão negativa para distender os sinusóides corporais e aumentar o influxo de sangue para o pênis. Dependendo de sua finalidade, o TV pode ser utilizado como dispositivo de constrição a vácuo (VCD), com o auxílio de um anel constritor externo que é colocado na base do pênis para evitar o escoamento do sangue, mantendo a ereção para a relação sexual. Podemos analisar como esses procedimento e feito na Figura 1.

Figura 1 - Dispositivo de Vacuoterapia

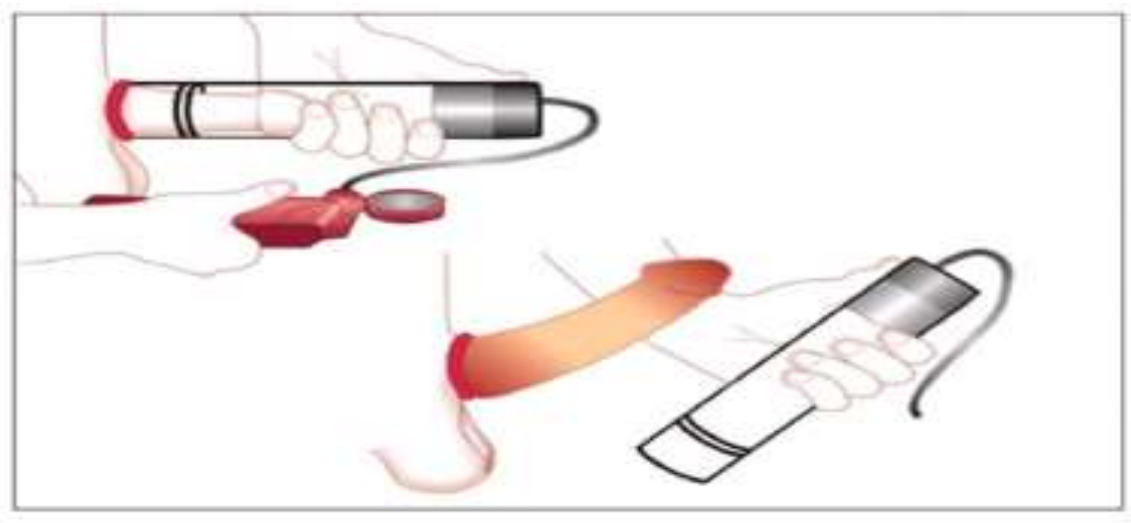

Fonte: Afif-Abdu (2007).

Além disso, como um dispositivo erétil a vácuo (VED), sem a aplicação de um anel de constrição, apenas aumenta a oxigenação do sangue para os corpos cavernosos e para outras finalidades. (Javaroni, 2018). 


\subsubsection{Terapia por ondas acústicas para DE}

O termo clínico para terapia por ondas de choque é terapia por ondas de choque de baixa intensidade. É uma terapia não invasiva usada na ortopedia há anos para ajudar a curar ossos quebrados, ligamentos e tendões feridos. (Biggers, 2017).

A terapia por ondas de choque é indolor para a maioria dos homens. E, como afirmado anteriormente, as pesquisas disponíveis encontraram poucos efeitos colaterais, se é que houve algum.

A terapia de choque de baixa intensidade também tem sido usado para melhorar a cicatrização de feridas. Usando ondas sonoras direcionadas de alta energia, o A terapia de choque de baixa intensidade pode acelerar o reparo de tecidos e o crescimento celular. (Javaroni, 2018).

\subsubsection{Exercícios de Kegel}

Os exercícios de kegel, ou exercícios pélvicos, provaram ser eficazes no tratamento da disfunção erétil e devem ser usados como tratamento de primeira linha. Os músculos isquiocavernoso e bulbocavernoso na região pélvica circundam o pênis e são ativos durante a ereção.

Segundo Sousa et al (2011), para a adesão da paciente ao tratamento e o sucesso da intervenção terapêutica é importante observar como cada uma percebe seu problema e as consequências trazidas pela patologia para sua vida, de forma que, mesmo apresentando sinais e sintomas semelhantes, possam adotar diferentes estratégias para enfrentar o problema. Dentre as estratégias, destacam-se as intervenções cirúrgicas e terapias conservadoras, como o exercício de Kegel. Os exercícios a seguir da figura 2 , visam fortalecer esses músculos.

Figura 2 - Exercícios de Kegel.

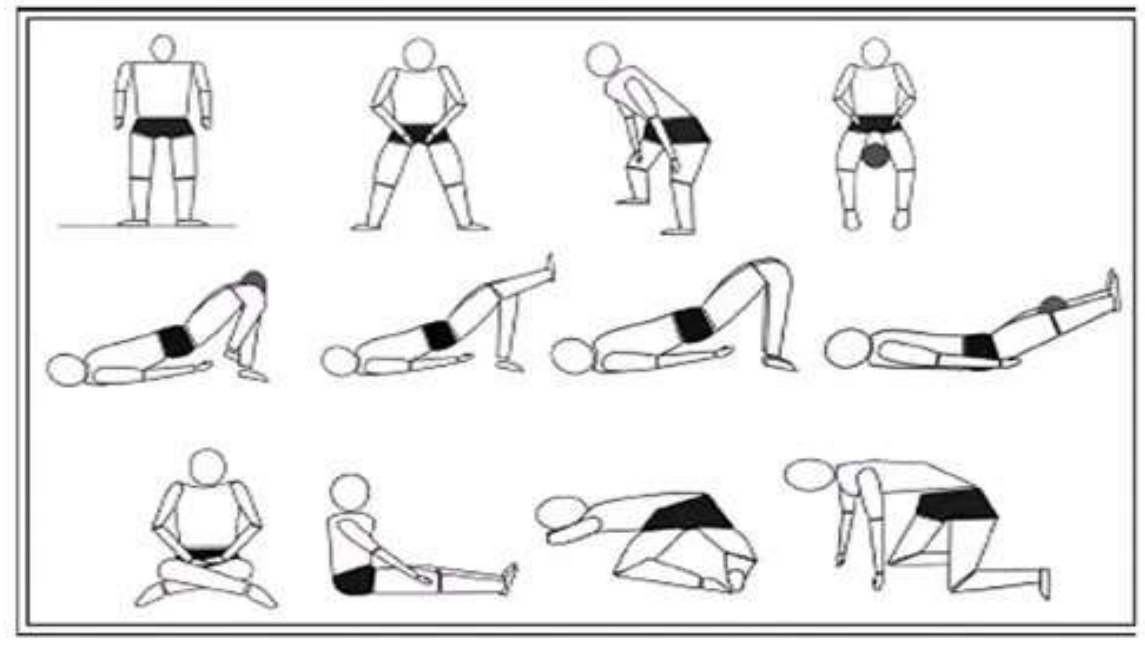

Fonte: https://comoengrossaropenis.com.br/exercicios-de-kegel.

Exercícios específicos e fisioterapia podem tratar a disfunção erétil. Os especialistas médicos recomendam que os homens que desejam melhorar ou restaurar sua função sexual façam exercícios de Kegel duas vezes ao dia. Kegels constrói o assoalho pélvico, tornando-o mais forte. $\mathrm{O}$ assoalho pélvico ajuda a tornar as ereções mais rígidas. Um homem também pode manter uma ereção por mais tempo porque um assoalho pélvico em forma pode pressionar um vaso sanguíneo essencial para manter o sangue no pênis durante a atividade sexual. Os exercícios fazem referência ao autoconhecimento da mulher, pois segundo Miranda e Kraievski (2017), são beneficiadas, com o aumento da autoestima sendo que o treinamento da MAP também faz com que aja aumento da libido e potencial orgástico, melhorando o relacionamento conjugal, pois a vida sexual do casal se torna mais prazerosa. 


\subsubsection{Fisioterapia do Assoalho Pélvico}

A fisioterapia do Assoalho pélvico pode tratar com sucesso problemas de natureza sexual ou pélvica. Um homem pode sofrer de disfunção erétil (DE) por hiper ou hipoatividade dos músculos pélvicos. A fisioterapia do assoalho pélvico pode tratar de problemas nas áreas lombo sacro-quadril e abdômen pélvica que podem causar disfunção erétil. Fisioterapeutas especializados podem avaliar os nervos, fáscias, órgãos e sistemas musculoesqueléticos nessas regiões para isolar as causas neuro musculoesqueléticas da disfunção erétil. Corrobora-se que a realização dos exercícios no assoalho pélvico assume papel importante na facilitação da obtenção do prazer sexual, pois trabalha a capacidade consciente de contrair a musculatura do assoalho pélvico o que é um fator que pode interferir na satisfação sexual feminina (Antonioli, Simões, 2010).

Os exercícios de fisioterapia do assoalho pélvico que enfocam os músculos do assoalho pélvico podem ser um componente valioso na restauração da função sexual. Um homem tem dois músculos do assoalho pélvico superficiais: o músculo bulbo cavernoso, que percorre cerca de um terço a metade do caminho ao redor da base do pênis, e o músculo isquio cavernoso. O músculo bulbo cavernoso executa estas três tarefas:

- O músculo pressiona a veia dorsal profunda para manter o sangue dentro do pênis durante uma ereção;

- Participa da ejaculação por bombeamento;

- Por meio da ação reflexa, o músculo esvazia a uretra do bulbar.

Quando um homem pratica fisioterapia do assoalho pélvico regularmente, ele fortalece os músculos do assoalho pélvico. Como resultado, ele pode desenvolver maior controle sobre suas ereções e desempenho sexual. Existe uma opção de terapia altamente eficaz que não envolve drogas, cirurgia ou qualquer procedimento invasivo para DE. (Biggers, 2017).

\subsubsection{Ozonioterapia}

$\mathrm{Na}$ ozonioterapia, é utilizada uma mistura oxigênio-ozônio, este gás usado, tem propriedades que conseguem aumentar a oferta de oxigênio para os tecidos. Foi comprovado por estudos científicos que a aglomeração típica de glóbulos vermelhos (eritrócitos) em doenças arteriais oclusivas é revertida pela terapia de ozônio através de alterações nas cargas elétricas da membrana eritrócito. Essa regeneração das condições elétricas normais da membrana promove a recuperação da flexibilidade e plasticidade dos eritrócitos, melhorando assim as propriedades reológicas do sangue, o que consequentemente favorece o transporte de oxigênio e, portanto, melhora a circulação sanguínea, chegando ao fim de um dos principais problemas que dão origem à impotência sexual, aumentando a qualidade da ereção, durabilidade, intensidade e frequência da relação sexual. (Javaroni, 2018).

\section{Conclusão}

A prática da relação sexual é um dos itens importantes para o ser humano ter uma vida social e pessoal satisfatória. Com tudo a disfunção erétil pode ocasionar vários transtornos ao indivíduo e impedir que tenho uma prática sexual prazerosa. Esse estudo traz vários recursos fisioterapêuticos eficazes, que podem, ser utilizados no tratamento da DE, de forma individualizada ou associados.

Diante disso, a fisioterapia é uma forma eficaz na prevenção e no tratamento da disfunção erétil, com métodos não invasivos, indolor e de fácil realização. Com base nas pesquisas realizadas, considera-se que a fisioterapia é eficaz na prevenção e no tratamento da disfunção erétil. Contudo, necessita-se de mais estudos para o aperfeiçoamento fisioterapêutico e descoberta de novas técnicas a ser utilizadas. 


\section{Referências}

Abreu, C. A (2015). A visão bioética diante do comportamento social na evolução do tratamento da disfunção erétil. Dissertação (mestrado).FAMERP.

Afif-abdo J (2007). Diagnóstico e tratamento da disfunção erétil. Diagn Tratamento.12(4):192-5. Portal regional da BVS.

Antonioli, R. S., \& Simões, D (2010)- Abordagem fisioterapêutica nas disfunções sexuais femininas; Revista Neurociências.

Biggers, A., (2017) Everything You Need to Know About Erectile Dysfunction (ED).

Bueno, M. B. T., \& Rombaldi. B. M. (2019) Percepções da Atuação Fisioterapêutica na Saúde do Homem: Revisão integrativa, Revista Saúde e Desenvolvimento Humano.7(3): 57-62.

Carboni C (2014) Efeitos da eletroestimulação funcional na disfunção erétil; Universidade Federal De Ciências Da Saúde De Porto Alegre - Ufcspa Curso De Pós-Graduação Em Ciências Da Reabilitação.

Carvalho L. M. A., \& Santos S. M. P. (2018) Benefícios dos exercícios de kegel nas disfunções sexuais causadas pelas alterações no envelhecimento: uma revisão integrativa da literatura; VI Congresso Internacional de Envelhecimento Humano.

Costa, M. R (2016) Fatores associados à disfunção erétil em pacientes portadores de doença renal crônica em tratamento conservador. Tese de doutorado apresentada à Universidade Federal de Goiás.

Delgado A. M., \& Ferreira I. S. V., \& Sousa, M. A (2015) Recursos Fisioterapêuticos Utilizados no tratamento das Disfunções sexuais femininas, recursos fisioterapêuticos Utilizados no tratamento das Disfunções sexuais femininas, 4(1), 47-56.

Diniz A. F. A., Ferreira, R. C., Souza, I. L., \& Silva, B. A (2020) Canais Iônicos como Alvos Terapêuticos Potenciais para Disfunção Erétil: Uma Revisão; Front Pharmacol.

Falchi \& Ricci S. L (2016) Prevalência e fatores associados à disfunção erétil na zona urbana de Pelotas/RS - Brasil, em homens com idade entre 40 e 70 anos. Dissetação de mestrado apresentado Universidade Católica de Pelotas, 2016. Femininas. Rev Neurocienc.

Javaroni, V. (2011) Disfunção erétil: sintomas, tratamentos e causas.

Lima M. P., et al (2016)- Disfunção erétil no homem idoso.

Mayo clinic (2017) Benign prostatic hyperplasia BPH.

Michiles, C. H (2010) Disfunção Erétil Atação do Médico e do Psicólogo.

Miranda B. F., \& Kraievski, E. S (2017) Pompoarismo: Os benefícios que traz para a vida da mulher,Rev Conexão Eletrônica, Três Lagoas-MG, vol.14, n1.

Moreira Jr et al (2014) Centro de Pesquisas Gonçalo Moniz, Salvador, Bahia.

Nascimento M. C. B., Queiroz C. R., Vasconcelos F. R. M., Barros L. L. S., \& Beuttenmüller, L (2016) Atuação do Fisioterapeuta, no tratamento da disfunção erétil - Revisão de Literatura; Anais do Congresso Brasileiro de Fisioterapia v.1 n.1.

Perez. F. S. B (2018) Fortalecimento perineal com um novo eletrodo móvel na incontinência urinária e disfunção sexual. Faculdade de Medicina da Universidade de Brasília.

Peterle P. J., \& Bueno F (2016)- Estudo analítico e comparativo de comprimidos contendo citrato de sildenafila adquiridos no mercado formal e informal. Revista Infarma Ciências Farmaceuticas. Caxias do Sul-RS.

Santos L. M (2013) Disfunção erétil: Uma abordagem fisioterapêutica, Faculdade de Educação e Meio Ambiente, Ariquemes-Ro.

Sarris A. B et al. (2016) Fisiopatologia, avaliação e tratamento da disfunção erétil: artigo de revisão. Rev Med (São Paulo).

Sousa J. G., et al (2011) Avaliação da força muscular do assoalho pélvico em idosas com incontinência urinária.Fisioter. mov.

Souza C. A., et al (2011) Importância do Exercício Físico no Tratamento da Disfunção Erétil; Rev Bras Cardiol.;24(3):180-185.

Stake R. E (2011)- Pesquisa qualitativa- Estudando como as coisas funcionam. Porto Alegre.

Theves J. A (2015) Avaliação da qualidade de citrato de sildenafila em amostras comercializadas de forma ilícita. Santa Cruz do Sul - RS, 2015.

Wespes E., et al (2002) Diretrizes para Disfunção Sexual Masculina: Disfunção Erétil e Ejaculação Prematura; Eur Urol; 49 (5): $806-15$. 